\title{
Fragment of tegument protein pp65 of human cytomegalovirus induces autoantibodies in $\mathrm{BALB} / \mathrm{c}$ mice
}

\author{
Ao-Ho Hsieh', Yí-Jyun Jhou², Chung-Ting Liang ${ }^{3}$, Mingi Chang ${ }^{4^{*}+}$ and Shih-Lien Wang ${ }^{2^{*+}}$
}

\begin{abstract}
Introduction: Human cytomegalovirus (HCMV) infection has been implicated in the development of autoimmunity, including systemic lupus erythematosus (SLE). Previously we reported that HCMV phosphoprotein 65 (pp65) could induce early onset of autoantibody and glomerulonephritis on lupus-prone NZB/W mice. This study further examined whether the B cell epitope(s) in pp65 is able to drive the development of autoantibody.

Methods: Sera from SLE patients or HCMVpp65-immunized mice were analyzed for anti-nuclear antibody by immunoblotting, enzyme-linked immunosorbent assay (ELISA), immunofluorescent stain and Crithidia luciliae stain. The deposition of immunoglobulin to the kidney was also examined by immunofluorescent stain. The interactions between pp65 sub-fragment to cellular proteins were revealed by yeast two-hybrid analyses.

Results: Our results showed that most SLE patients possessed antibodies to the C-terminal half of the HCMVpp65 antigen. Of these positive sera, $73 \%$ were also positive to the pp65 $336-439$ sub-fragment. The immunization of pp65 $336-439$ induced formation of multiple anti-nuclear antibodies, including anti-chromatin, anti-centriole, antimitotic spindle type I/II (MSA I/II) and a significant elevation of anti-double-stranded DNA (anti-dsDNA) antibodies on BALB/c mice. Yeast two-hybrid analyses revealed the binding of pp65 $336-439$ sub-fragment to cellular proteins. Immunoglobulin deposition on glomeruli was also detected on pp65 $336-439^{-i m m u n i z e d ~ m i c e . ~}$
\end{abstract}

Conclusions: Our data suggested that HCMVpp65 ${ }_{336-439}$ sub-fragment may induce cross-reactive antibodies to several nuclear antigens, which could contribute to the development of autoimmunity in genetic-suspected individuals.

\section{Introduction}

The Epstein-Barr virus (EBV)-infection-induced systemic lupus erythematosus (SLE)-specific autoantibody is one of the best examples for cross-reactive antibody mediated autoimmunity [1]. In those studies, autoantibodies to Smith antigen B/B' $\left(\mathrm{SmB} / \mathrm{B}^{\prime}\right)$ and clinical symptoms that resemble SLE were induced by normal strains of mice following immunization of octapeptide (PPPGRRP) [2]. The amino acid sequence is not a reliable indicator to predict cross-reactivity because antibodies to amino acid

\footnotetext{
* Correspondence: mingi.chang@gmail.com; wangsltw@mail.tcu.edu.tw + Contributed equally

${ }^{2}$ Institute of Microbiology Immunology and Biochemistry, Tzu-Chi University, No. 701, Sec. 3, Zhongyang Rd., Hualien City, Hualien County 970, Taiwan ${ }^{4}$ Development Center of Biotechnology, No.101, Ln. 169, Kangning St., Xizhi Dist, New Taipei City 221, Taiwan

Full list of author information is available at the end of the article
}

52 to 72 of Epstein-Barr virus nuclear antigen 1 (EBNA$1_{52-72}$ ) also cross-reacted to amino acid 169 to 180 of Ro antigen $\left(\mathrm{Ro}_{169-180}\right)$ disregard significant differences of both sequences [3].

HCMV belongs to the Betaherpesvirinae family and is an opportunistic pathogen that could cause severe clinical consequences in individuals with impaired immune systems [4]. Specific activation of both viral-specific and auto-reactive $\mathrm{T}$-cells during infection has been shown to accelerate the development of type I diabetes [5,6]. HCMV-infection-induced Ro60 antigen expression on the cell surface and elevated anti-phospholipid antibody has been reported $[7,8]$. In addition, a higher prevalence of autoantibody to U1 small nuclear ribonucleoprotein (U1 snRNP) in SLE patients and animals are associated with HCMV infection or immunization, respectively $[9,10]$. The tegument phosphoprotein 65 (pp65, UL83) of

\section{Biomed Central}

(c) 2011 Hsieh et al., licensee BioMed Central Ltd. This is an open access article distributed under the terms of the Creative Commons Attribution License (http://creativecommons.org/licenses/by/2.0), which permits unrestricted use, distribution, and reproduction in any medium, provided the original work is properly cited. 
HCMV is the most abundant phosphoprotein on the virion and an immunodominant target to both $\mathrm{CD}_{4}^{+}$and $\mathrm{CD}^{+} \mathrm{T}$ cells $[11,12]$. Two $\mathrm{T}$-cell dominant regions, pp65303-388 and pp65477-561, located on the C-terminus of pp65, have been reported and at least 28 CTL epitopes were verified within the CMVpp65 [13,14].

It has been demonstrated that in addition to activating T-cells, immunization of pp65 encoded plasmid could induce early onset of autoantibody activity and glomerulonephritis on lupus-prone animals [15]. The anti-pp65 antibody activity is not a common feature of healthy individuals, only $11.11 \%$ normal sera (sera from healthy donors) possess antibodies to pp65 antigen [15]. Immunization of pp65 antigen or its fragments in Freund's adjuvant to BALB/c mice only elicited anti-pp65 activity for a limited time [15]. The C3d is a degraded peptide of the third complement complex protein and ligand to complement receptor 2 (CR2/CD21). Because of its CD21 binding property, C3d has been used as an adjuvant to enhance the immunization efficiency or to activate anergic $B$ cells [16-18]. Here, we reported that immunization of pp65336-439 with C3d as adjuvant to BALB/c mice induced diverse nuclear-targeting autoantibodies and immunoglobulin deposition on glomeruli. Moreover, pp65336-439 induced immunity cross-reacts to multiple cellular proteins suggesting that immune responses to pp65336-439 may instigate autoimmunity.

\section{Materials and methods}

\section{Human sera}

This study involving human subjects was approved by the Tzu-Chi University, National Science Committee and the National Blood Center or Taichung Veteran Hospital Review Boards and approved by the Committee of Ethics in Tzu-Chi University [15]. A selected portion of patients' sera were removed from this study subsequently due to restriction from Institutional Review Boards. All subjects in this study gave their informed consents. Patients were classified based on the classification criteria of the American College of Rheumatology as SLE $(n=61)$, rheumatoid arthritis (RA, $n=50$ ), Sjögren's syndrome (SS, $n=$ $13)$ and systemic sclerosis (SSc, $n=20)$. Normal sera $(n=$ 45) were collected from qualified, sex- and age-matched adult blood donors.

\section{Mice}

Normal six- to eight-week-old female BALB/c mice were purchased from the National Laboratory Animal Center (NLAC), Taipei, Taiwan. Animals were housed in a pathogen-free facility with an independent ventilation cage system at the Laboratory Animal Center of TzuChi University, Hualien, Taiwan. All animal experiments were approved by Tzu-Chi University Animal Experimental Ethics Committee (reference number 94-A-06).

\section{Constructions and expression plasmids}

The pp651-167, pp65 167-336 and pp65 $5_{336-561}$ sequences are amplified using the following primer pair sequences, respectively listed in Table 1 . The sequences were designed using the published nucleotide sequence of pp65 (strain: AD-169, GenBank: FJ527563). The fragments of pp651-167, pp65 167-336, and pp65336-561 were prepared from PCR and digested by restrictive enzymes, and then ligated into pET30. The pp65 336-379, pp65 $379-455$ and pp65 $455-561$ fragments were digested from pp65 $336-561$ to form 132-bp (BamHI/HindIII), 231-bp (HindIII/NotI) and 321-bp (NotI/XhoI) fragments, respectively. The pp65 $336-422$, pp65 $336-439$ and pp65 $336-448$ encoding sequences were amplified from a pp65 $336-561$ clone using both upstream and downstream primers (Table 1). The pp65 sub-fragments mentioned above were cloned and inserted into pET30. The murine C3d encoding sequence (GenBank: DQ408205) was PCR amplified with C3d primers and ligated into pET32 (Table 1). For yeast two-hybrid analysis, PCR product of pp65 $336-439$ was cloned into pAS-1 plasmid to create a pAS-1-pp65336-439-binding domain (BD) plasmid.

\section{Antigen preparation, biotinylation and streptavidin conjugation}

Recombinant proteins were over-expressed in E. coli with $1 \mathrm{mM}$ isopropyl $\beta$-D-thiogalactoside (IPTG, SigmaAldrich, St. Louis, MO, USA) induction and purified by nickel affinity column. The C3d biotinylation and streptavidin (SA) conjugation (Pierce, Thermo Scientific, Rockford, IL, USA) were performed by the manufacturers' instructions. In brief, maleimide-activated streptavidin (Pierce) was conjugated with proteins containing reduced disulfide bonds from a disulfide reducing gel (Pierce) and mixed with biotinylated C3d to form the protein-SA-C3d tetramer, including pp65 $1-167$, pp65 $336-439$ and SA-C3d only. Tetramers were generated and prepared for immunization within four hours.

\section{Immunization and sera collection}

A total of 35 six- to eight-week-old female BALB/c mice were randomly separated into groups of pp65 $5_{1-167}-\mathrm{C} 3 \mathrm{~d}(n$ $=11)$, pp65336-439-C3d $(n=17)$, SA-C3d $(n=5)$ and PBS $(n=2)$. Mice were inoculated intraperitoneally with $50 \mu \mathrm{g}$ pp65 $336-439^{-C} 3 d$ or pp65 $1-167-$ C3d, or SA-C3d in complete Freund's adjuvant (Complete Freund's Adjuvant, SigmaAldrich) or phosphate-buffered saline (PBS, $3.2 \mathrm{mM}$ $\mathrm{Na}_{2} \mathrm{HPO}_{4}, 0.5 \mathrm{mM} \mathrm{KH} \mathrm{PO}_{4}, 1.3 \mathrm{mM} \mathrm{KCl}, 135 \mathrm{mM} \mathrm{NaCl}$, $\mathrm{pH}$ 7.4). Boosting was performed with antigens in incomplete Freund's adjuvant (Incomplete Freund's Adjuvant, Sigma-Aldrich) three times in three weeks. Mice were bled via the retro-orbital vein one day prior to each assay and at two-week intervals. Unused sera were stored at $-20^{\circ} \mathrm{C}$ and the diluted sera for use were kept at $4^{\circ} \mathrm{C}$. 
Table 1 Primers sets for the truncation of HCMVpp65 antigen constructions

\begin{tabular}{|c|c|c|c|}
\hline \multirow[t]{2}{*}{ Clones } & \multicolumn{2}{|c|}{ Sequences } & \multirow[t]{2}{*}{ Vectors } \\
\hline & Forward (5- > 3) & Reverse $(5->3)$ & \\
\hline pp65 $1-167$ & ATG GAT CCA TGG AGT CGC GCG GTC GCC G & CCG GAA TTC CAG TCC CGA GAC CGT GAG GAC CGT & pET30 \\
\hline pp65167-336 & CGC GGA TCC TGG ACG CGT CAG CAG ACC CA & CGC GGA TCC CTC GCG TAT GGC TTG TAC CT & pET30 \\
\hline $\mathrm{pp} 5_{336-561}$ & CGC GGA TCC ACC GTG GAA CTG CGT CAG TA & TAG GAT CCA CCT CGG TGC TाT TTG GGC G & pET30 \\
\hline $\mathrm{pp} 65_{336-448}$ & CGC GGA TCC ACC GTG GAA CTG CGT CAG TA & 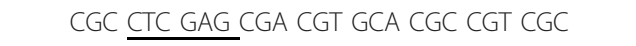 & pET30 \\
\hline pp65336-439 & CGC GGA TCC ACC GTG GAA CTG CGT CAG TA & 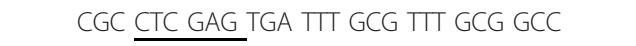 & pET30 \\
\hline $\mathrm{pp} 65_{336-422}$ & CGC GGA TCC ACC GTG GAA CTG CGT CAG TA & 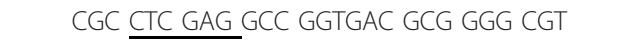 & pET30 \\
\hline murine $\mathrm{C} 3 \mathrm{~d}$ & CGC GAT ATC ACC CCC GCA GGC TGT GGG GAA C 3' & CGC GGA TCC GGA TCC GCT ACG GCT GGG GAG & pET32 \\
\hline pp65 $636-439$ & CGC GGA TCC ACC GTG GAA CTG CGT CAG TA & CGC CTC GAG TGA TाT GCG TाT GCG GCC & pAS-1 \\
\hline
\end{tabular}

The underlined sequences mean the usage of restrictive enzyme

\section{Immunoblotting and enzyme-linked immunosorbent assay}

Immunoblotting was performed as previously described [15]. In brief, $1 \times 10^{8}$ cultured HeLa cells or $2 \mu \mathrm{g}$ purified HCMV were prepared, homogenized and separated by $12 \%$ sodium dodecyl sulfate polyacrylamide gel electrophoresis (SDS-PAGE/slab gel format). Separated proteins were transferred to nitrocellulose paper and blocked by $5 \%$ skim milk then analyzed with mice or human sera at dilutions of $1: 500$ or $1: 1,000$ in PBS. The antibody reactivity was detected by horseradish peroxidase (HRP) conjugated secondary antibody (Jackson ImmunoResearch Laboratories, West Grove, PA, USA) and chemiluminescent detection agents (Perkin Elmer, Norwalk, CT, USA).

ELISA was performed as previously described [15]. In brief, for the anti-dsDNA antibody assay, $1 \mu \mathrm{g} /$ well of purified calf thymus dsDNA (Sigma-Aldrich) in $\mathrm{ddH}_{2} \mathrm{O}$ was coated to a microtiter plate (Corning, Lowell, MA, USA). After blocking with 5\% skim milk, mice or human sera at 1:100 and 1:1,000 dilutions in PBS, respectively, were added and incubated at room temperature (RT) for two hours. At the end of incubation, the plate was washed and bound antibodies were detected by HRP conjugated secondary antibodies at dilutions of 1:10,000 (for anti-dsDNA IgG) or 1:2,000 (for anti-dsDNA IgG subtypes, Bethyl Laboratories, Montgomery, TX, USA, purified HCMV or $1 \mu \mathrm{g} /$ well of HeLa lysate in PBS were coated on a microtiter plate at $4^{\circ} \mathrm{C}$ overnight [15]. After the plate was skim-milk-blocked, mouse or human sera were added at dilutions of 1:500 or 1:1,000, respectively, in PBS and incubated at $4{ }^{\circ} \mathrm{C}$ for two hours. The bound antibodies were detected by a secondary antibody at dilutions of $1: 10,000$ at $4^{\circ} \mathrm{C}$ for two hours. The o-phenylenediamine dihydrochloride (OPD, Sigma-Aldrich) was used as the substrate and HRP activity was read at $450 \mathrm{~nm}$ with a micro-ELISA reader (DYNEX MRX II).

For the detection of protein-to-protein interaction between pp65 $336-439$ and HeLa proteins, whole HeLa extract $\left(1 \times 10^{8}\right.$ cultured HeLa cells) was separated by
12\% SDS-PAGE/slab-gel and transferred onto nitrocellulose paper. Before the experiment, the blot was cut into strips, skim-milk-blocked and then incubated with either pp65 $336-439$ or pp65 $5_{1-167}$ His-tag fusion protein at concentrations of $20,10,5,2.5,1.25,0.625 \mathrm{mg} / \mathrm{ml}$ or at concentrations of $20,10,5,2.5 \mathrm{mg} / \mathrm{ml}$, respectively for one hour. The pp65336-439 or pp651-167 bound HeLa proteins were detected by 10,000X diluted HRP-conjugated mouse anti-His tag IgG (Serotec, Raleigh, NC, USA) after one hour of incubation. The reactions were visualized by chemiluminescent detection agents.

\section{Immunofluorescence}

Mouse sera were tested for anti-nuclear antibodies (ANAs) at a dilution of 1:100 in PBS by a standard antinuclear antibody (ANA) test (Binding site). The reactivity of anti-dsDNA antibody was tested by immunofluorescent stain using the Crithidia luciliae test (binding site) with mice sera at a dilution of 1:40 in PBS, as suggested by the manufacturer. In brief, $25 \mu \mathrm{l}$ of diluted mice sera were incubated with slide-coated HEp-2 or Crithidia luciliae for 20 minutes in humid chamber at RT. HEp-2 or Crithidia luciliae slides were washed three times in PBS at RT for 10 minutes each. The bound antibodies were detected by 100X diluted Fluorescein isothiocyanate (FITC)-conjugated anti-mouse IgG (Jackson ImmunoResearch Laboratories) for 20 minutes in a humid chamber at RT in the dark. For nuclear visualization, HEp-2 slide was incubated in $25 \mu \mathrm{l}$ of DAPI $(0.5 \mu \mathrm{l} / \mathrm{ml}$, Sigma-Aldrich $)$ at RT for two minutes in the dark. At the end of staining, slides were washed (PBS) and mounted (mounting medium) for investigation by Nikon E800 fluorescence microscopy (Nikon, Tokyo, JP).

For an immunofluorescent stain on glomerulus, kidneys were removed from mice, immediately placed in the OCT gel and frozen at $-80^{\circ} \mathrm{C}$ for 24 hours. The 5 -mm-thick frozen sections were stained with FITC-conjugated antimouse IgG at a 1:100 dilution in PBS for 20 minutes in a humid chamber at RT in the dark. After PBS washing, coverslips with mounting medium on tissue slides were 
prepared for investigation by Nikon E800 fluorescence microscopy.

\section{Antibody purification}

Moderated Cyanogen bromide $(\mathrm{CnBr})$ powder (SigmaAldrich) was activated as described by the manufacturer. In brief, purified and sonicator-homogenized HCMV virions were dissolved in a coupling buffer $\left(0.1 \mathrm{M} \mathrm{NaHCO}_{3}\right.$, $0.5 \mathrm{M} \mathrm{NaCl}, \mathrm{pH} 8.3$ ) with activated $\mathrm{CnBr}$ gel at $4^{\circ} \mathrm{C}$ overnight. The free active groups on $\mathrm{CnBr}$ were deactivated by 0.1 M Tris- $\mathrm{HCl}$ (pH 8.0) at RT for two hours. After deactivation, $\mathrm{CnBr}$ gel was washed with alternating buffer $(0.1 \mathrm{M}$ $\mathrm{NaAc}, 0.5 \mathrm{M} \mathrm{NaCl}, \mathrm{pH} 4.0$ and $0.1 \mathrm{M}$ Tris- $\mathrm{HCl}, 0.5 \mathrm{M}$ $\mathrm{NaCl}, \mathrm{pH} 8.0$ ) twice and washed with $10 \mathrm{ml}$ PBS once. For purification, $200 \mu \mathrm{l}$ of pooled pp65 $336-439$ or pp651-167 mouse sera in $10 \mathrm{ml}$ PBS were added to HCMV-CnBr gel and rolled at $4^{\circ} \mathrm{C}$ overnight. The unbound portion of sera, flow through, was collected and concentrated as a negative control, while bound antibodies were eluted by $1 \mathrm{ml}$ of $0.1 \mathrm{M}$ glycine ( $\mathrm{pH}$ 2.0) [19]. The eluted samples were neutralized immediately with a $30 \mu \mathrm{l}$ of neutralizing buffer (1 M Tris- $\mathrm{HCl}, 2 \mathrm{M} \mathrm{NaCl}, \mathrm{pH} 8.8$ ).

\section{Yeast two-hybrid screening}

The Matchmaker yeast two-hybrid screening system (Clontech. Mountain View, CA, USA) was used to identify the proteins that were able to interact with pp65336-439 peptide. In this system, yeast two-hybrid library screening using yeast mating was performed as modified from the manufacturer's manual. The DNA fragment encoding pp65 336 -439 was cloned into the Gal4BD (DNA-binding domain of the transcription factor Gal4) vector pGBT-7 and the resulting plasmid was designated as BD-pp65 $336-$ 439. The BD-pp65 $336-439$ plasmid was transformed into the yeast strain AH109 (MATa) for screening the yeast library strain (Clontech Co.), which is the yeast strain Y187 (Mat $\alpha$ ) transformed with the AD-cDNA plasmid, HeLa cDNA cloned into the AD (activation domain of Gal4) vector pGAD-T7. The AH109 cells bearing BD-pp65 $336-$ 439 were cultured in the synthetic dextrose medium lacking tryptophan at $30^{\circ} \mathrm{C}$ until O.D.600 was approximately 0.8. The AH109 cells bearing BD-pp65 $336-439$ were then collected and mated with the yeast library strain in $2 \mathrm{X}$ YPDA medium (1\% Bacto yeast extract, $2 \%$ Bacto peptone, $2 \%$ Dextrose, $4 \%$ Adenine hemisulfate) at $30^{\circ} \mathrm{C}$. After mating, cells were screened on the synthetic dextrose solid medium lacking leucine, tryptophan and histidine (SD/$\mathrm{L} /-\mathrm{W} /-\mathrm{H})$ to assay expression of reporter gene HIS3 at $30^{\circ}$ C. The screened colonies were further screened on the synthetic dextrose solid medium lacking leucine, tryptophan, histidine and adenine (SD/-L/-W/-H/-A) to assay expression of reporter genes $H I S 3$ and $A D E 2$ at $30^{\circ} \mathrm{C}$. The AD-cDNA plasmid was isolated from the screened colony grown on the $\mathrm{SD} /-\mathrm{L} /-\mathrm{W} /-\mathrm{H} /-\mathrm{A}$ solid medium and transformed into E. coli for amplification. To further confirm the interaction between pp65336-439 peptide and the cDNA-encoding protein, both BD-pp65 $336-439$ plasmid and the purified $\mathrm{AD}$-cDNA plasmid were transformed into yeast strain YRG2 (Stratagene, La Jolla, CA, USA) and tested on the $\mathrm{SD} /-\mathrm{L} /-\mathrm{W} /-\mathrm{H}$ solid medium containing 15 $\mathrm{mM} 3$-aminotriazole to assay for the expression of the reporter gene $H I S 3$ at $30^{\circ} \mathrm{C}$. The purified AD-cDNA plasmid was then sequenced after confirmation.

\section{Statistical analysis}

Statistical methodology for differences of titer and prevalence in test results was analyzed by GraphPad Prism (GraphPad Software Inc. La Jolla, CA, USA) and using the Student $t$-test and Fisher's two-tailed exact test, respectively. Results with a $P$-value of $<0.05$ were considered to be significant.

\section{Results}

The pp65 $5_{336-439}$ sub-fragment of HCMV contains a B cell epitope(s) targeted by IgG from SLE patients

To verify the existence of B-cell epitope(s), HCMVpp65 tegument protein (pp65) was cloned, truncated and expressed as his-tagged fragments (pp65 $5_{1-167}$, pp65 167-336 and pp65336-561) that covered the entire antigen (Figure 1). Results showed that HCMV-seropositive SLE patients responded strongly to pp65 $336-561(61 \%, 37 / 61)$ compared to pp65 $65_{1-167}(7 \%, 4 / 61)$ or pp65 $65_{167-336}(20 \%, 12 / 61)$. The elevated positive rate to pp65 $336-561$ by SLE patients' sera was not found on either healthy or other disease controls (Table 2). In order to reveal the dominant epitope(s) within pp65 $336-561$, pp65 $336-561$ was sub-cloned into three fragments, expressed and re-screened (Figure 1). Of the original 37 pp65336-561-positive sera, 7 were removed from subsequent tests due to various availability issues. Of the rest of the 30 pp65336-561-positive sera, 22 were positive to pp65 $379-455$ (73\%, 22/30), 3 were positive to pp65 $455-561(10 \%, 3 / 30)$ and 0 was positive to pp65 $336-379$ (Table 2). Subsequently, pp65336-448, pp65336-439 and pp65 $336-422$ fragments were created by partial deletion from the C-terminus of pp65 $336-561$ (Figure 1). Of 22 pp65 $379-455^{-p o s i t i v e ~ s e r a, ~} 17$ were positive to pp65336-448 (77\%, 17/22), 16 were positive to pp65 $336-439(73 \%, 16 / 22)$ and 9 were positive to pp65 $336-422(41 \%, 9 / 22)$. The seroreactivity to three fragments (pp65 $336-422$, pp65336-439 or pp65 $336-448$ ) by pp65379-455 positive sera was listed in Table 3.

\section{Induction of anti-HCMV antibody and anti-HeLa protein antibody}

Although pp65 antigen immunized BALB/c animals possessed anti-pp65 antibodies and enhanced autoantibody activities, the titers were reduced in a few weeks after immunization [15]. To improve the immunogenicity of 


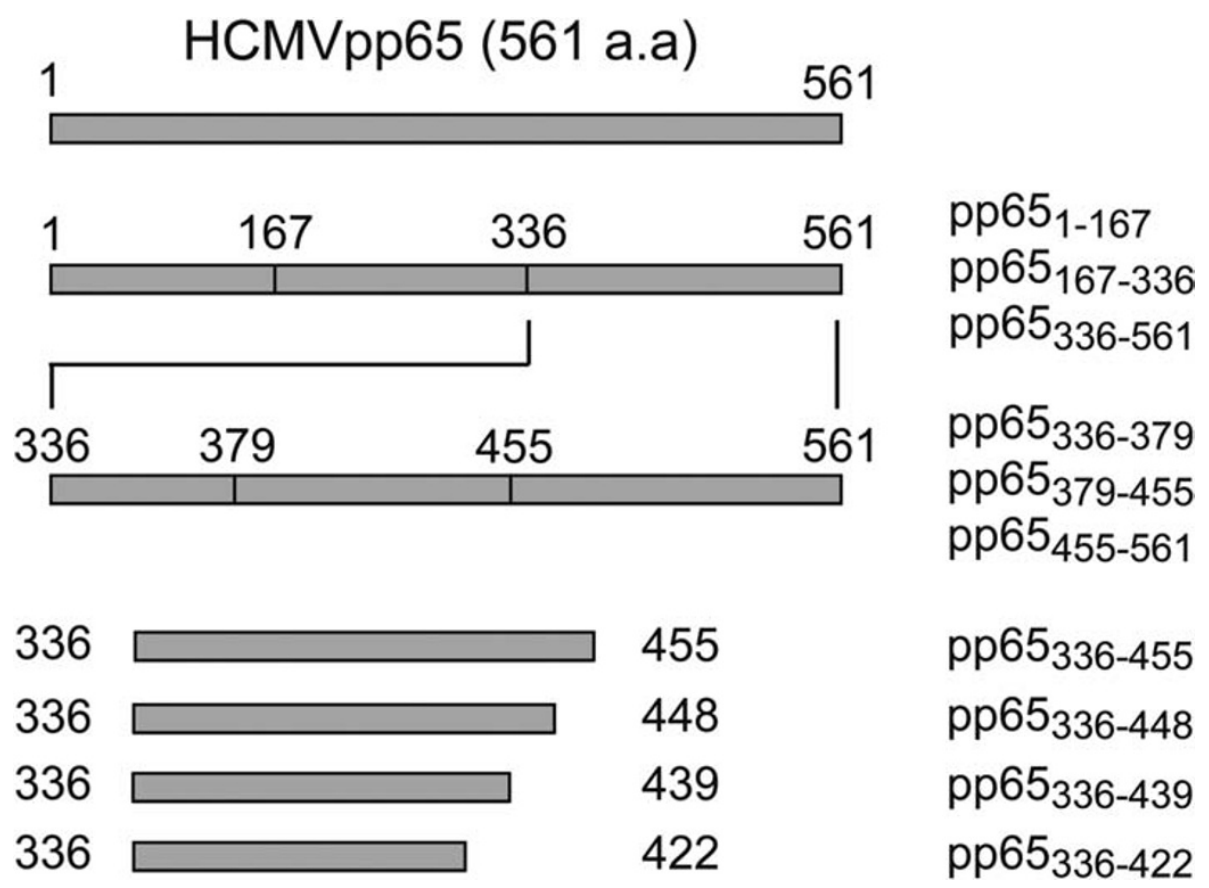

Figure 1 Schematic representation of truncated HCMVpp65 His-tag fusion proteins (Swiss-Prot: P06725). The full-length of HCMVpp65 is given in the top figure. Below that, six pp65 sub-fragments, pp65 $1-167$, pp65 167-336, pp65 $336-561$, pp65 $336-379$, pp65 $379-455$, pp65 $455-561$, and four $C$ terminal truncated peptides, pp65 $336-422$, pp65 $336-439$, pp65 $336-448$, pp65 $336-455$, are shown. The name of the plasmids which encoded pp65 subfragment proteins are given at the right. HCMVpp65, human cytomegalovirus phosphoprotein 65 (65 kD).

pp65, C3d was used as an adjuvant. The immunization results showed that pp65 $336-439$-immunized mice gradually increased developed anti-HCMVpp65 IgG reactivity started at four weeks and continued to the end of the experiment (12 weeks post-immunization, Figure 2a, b). In contrast, the titer of anti-HCMVpp65 IgG was significantly less for pp651-167-immunized mice (Figure 2a). The anti-HCMVpp65 IgG was not detected from either SA-C3d or PBS challenged mice (Figure 2b). Quasi- quantitative analysis showed that the titers of antiHCMVpp65 IgG from pp65 $336-439$ immunization was twice as much as sera from either pp651-167 (pp65336-439 vs. pp $65_{1-167}, 0.78 \pm 0.02$ vs. $0.44 \pm 0.05, P<0.0001$ ) or SA-C3d (pp65336-439 vs. pp651-167, $0.78 \pm 0.02$ vs. $0.43 \pm$ $0.02, P<0.0001)$ immunized animals at eight weeks post-immunization (Figure $2 \mathrm{a}$ ). The IgG reactivity to HCMV of pp651-167 and SA-C3d was statistically insignificant.

Table 2 The prevalence of antibody to HCMVpp65 sub-fragments in patients with autoimmunity and healthy controls

\begin{tabular}{|c|c|c|c|c|c|c|}
\hline & Antigens & SLE & SSc & SS & RA & Normal \\
\hline Age (years) & & 11 to 77 & 48 to 79 & 14 to 79 & 21 to 81 & 31 to 73 \\
\hline Mean (years) & & 33.8 & 61.9 & 53.4 & 54.6 & 63.2 \\
\hline Total specimen & & 61 & 20 & 13 & 50 & 45 \\
\hline Female (\%) & & 93.4 & 95 & 92.3 & 80 & 57.8 \\
\hline \multirow[t]{9}{*}{ Responsiveness } & pp651 to 167 (\%) & $4 / 61(7)$ & $3 / 20(15)$ & $5 / 13(38)$ & $0 / 50(0)$ & 6/45 (13) \\
\hline & pp65 167 to $336(\%)$ & $12 / 61(20)$ & $5 / 20(25)$ & $3 / 13(23)$ & $16 / 50(32)$ & $9 / 45(20)$ \\
\hline & pp65 336 to $561(\%)$ & $37 / 61(61)$ & $4 / 20(20)$ & 2/13 (15) & $7 / 50(14)$ & $2 / 45(4)$ \\
\hline & pp65 336 to $379(\%)$ & 0/30 (0) & & & & \\
\hline & pp $65_{379}$ to $455(\%)$ & $22 / 30(73)$ & & & & \\
\hline & $\mathrm{pp} 65_{455}$ to $561(\%)$ & $3 / 30(10)$ & & & & \\
\hline & pp65 336 to $448(\%)$ & $17 / 22(77)$ & & & & \\
\hline & pp65 $_{336}$ to $439(\%)$ & $16 / 22(73)$ & & & & \\
\hline & pp65 336 to $422(\%)$ & 9/22 (41) & & & & \\
\hline
\end{tabular}

RA, rheumatoid arthritis; SS, Sjögren's syndrome; SSc, systemic sclerosis. For immunoblot and ELISA assay, detection of anti-pp65 sub-fragments antibody was tested with purified human cytomegalovirus (HCMV) virions, as described in materials and methods. The HCMV positivity is defined by mean +3 s.e.m of normal control. The results are representative of triplicated experiments. 
Table 3 The sero-reactivity to pp65 sub-fragments by pp65 $379-455$ positive sera

\begin{tabular}{cccc}
\hline \multicolumn{3}{c}{ Sero-reactivity to antigens } & \multicolumn{2}{c}{ Patient number } \\
pp65 $336-422$ & pp65 $_{336-439}$ & pp65 \\
336-448 & $n=22$ \\
\hline+ & + & + & $1,4,5,9,13,17,18,19,22$ \\
- & + & + & $7,10,11,12,14,16,20$ \\
+ & - & + & \\
+ & + & - & 21 \\
- & - & + & \\
- & + & - & \\
+ & - & - & $2,3,6,8,15$ \\
- & - & - & \\
\hline
\end{tabular}

+, positive; -, negative

In order to demonstrate that the immunization of pp65 $336-439$ could lead to the development of cross-reactive autoantibodies, total HeLa lysate was prepared as the substrate for the detection of anti-HeLa antibodies (Figure 2c). Although immunization of pp65 $336-439$ and pp65 1 167 induced anti-HeLa IgG at 4 weeks and continued to 12 weeks post-immunization, pp65 $5_{336-439}$ immunization exhibited significantly higher anti-HeLa IgG activity than pp651-167 immunization (pp65336-439 vs. pp65 $1-167,0.50 \pm 0.03$ vs. $0.38 \pm 0.02, P=0.0191)$ at 8 weeks post-immunization. To exclude the possibility of HCMV contamination, HeLa lysate were immunoblotted by pp65 sub-fragment immunized sera (Figure $2 \mathrm{~d}$ ). The results showed that of eight anti-pp65 positive sera, only one strongly and another weakly react to HeLa antigens at $65 \mathrm{kD}$ position.

\section{Induction of anti-nuclear antibody (ANA) by pp65 $336-439^{-}$ immunization}

To determine if pp65 $336-439$ immunization could induce antibodies against nuclear components from HeLa cells, the anti-nuclear antibody (ANA) test was performed. The results showed that pp65336-439 immunization induced multiple ANA staining patterns, including speckled (5/17, Figure 3a, i), nucleosome (4/17, Figure 3b, j), chromatin (4/17, Figure 3c, k), mitotic spindle type I (MSA I, 4/17, Figure 3d, 1), mitotic spindle type II (MSA II, 10/17, Figure $3 e, m)$ centriole (6/17, Figure 3f, n) and nucleolar (14/17, Figure $3 g, o)$ stains at 1:100 dilution at 8 weeks and continued to 12 weeks post-immunization. In several occasions, ANA patterns were detected at dilution as much as 500 -fold. Nuclear stains, however, were not detected from either SA-C3d or PBS-immunized animals (0/5, 0/2, Figure $3 \mathrm{~h}, \mathrm{p})$. Four pp651-167-immunized mice developed weak anti-nucleolar reactivity $(4 / 11$, Figure $3 g$, o) detectable at 1:40 dilution. Taken together, pp65336-439 immunization could induce cross-reactive antibodies to multiple nucleus components (Table 4).

\section{Induction of anti-dsDNA antibody by pp65 ${ }_{336-439}$ immunization}

Anti-dsDNA antibody is a feature and a disease indicator for SLE patients [20-22]. ELISA assays showed that pp65336-439-immunized sera exhibited significantly enhanced anti-dsDNA antibody activity compared to animals immunized with pp65 $65_{1-167}$ (pp65 636 -439 vs. pp65 $167,0.66 \pm 0.02$ vs. $0.48 \pm 0.03, P<0.0001)$, or SA-C3d (pp65 $336-439$ vs. SA-C3d, $0.66 \pm 0.02$ vs.0.42 $\pm 0.02, P<$ 0.0001 ) at 8 weeks and continued to 12 weeks postimmunization (Figure 4a). The differences of anti-dsDNA antibody between pp65 $1-167$ and SA-C3d immunized mice were insignificant. The IgG2a to dsDNA is the dominant isotype to SLE nephritis [23]. ELISA-based assays showed that 13 of 17 pp65 $5_{336-439}$ immunized mice were positive to dsDNA. Isotyping showed that enhanced IgG1 (dsDNA (+) IgG1 vs. dsDNA (-) IgG1, $0.50 \pm 0.02$ vs. $0.35 \pm 0.03, P=0.0029$ ) and IgG2a isotypes (dsDNA (+) IgG2a vs. dsDNA (-) IgG2a, $0.33 \pm 0.02$ vs. $0.22 \pm$ $0.02, P=0.0134$ ) were the contributors of anti-dsDNA activity (Figure 4b). To confirm the ELISA-based antidsDNA analysis, the Crithidia luciliae stains were performed. Of 17 pp65336-439-immunized animals, 11 were positive for anti-dsDNA antibody (1:40 dilution) at 8 weeks and continued to 12 weeks post-immunization, compared to 2 of 11 pp65 $5_{1-167}$-immunized mice (Figure 4c). All Crithidia luciliae-positive sera were positive at ELISA tests. Only one pp651-167-immunized mouse was positive for Crithidia luciliae at 12 weeks post-immunization (Figure 4d).

\section{The elevated anti-HCMV pp65 $5_{336-439}$ antibody is cross-} reactive to dsDNA and nucleus components

To elucidate the relation between pp65 $336-439$ immunization and anti-nuclear antibody found in animals, antibodies to either pp65336-439 or pp65 $65_{1-167}$ were affinity purified from pooled pp65336-439 or pp65 $65_{1-167}$ immunized mouse sera. The results showed that affinity-purified pp65 $336-439$-specific IgG exhibiting significantly enhanced anti-HCMV activity compare to pp65 $5_{1-167}$ specific IgG (pp65 $336-439$ vs. pp65 $1-167,1.08 \pm 0.05$ vs. $0.27 \pm 0.01, P<$ 0.0001 , Figure 5a). Unbound fractions (flow through) from purification processes remain anti-HCMV positive, but the titer reduced significantly (pp65 $336-439$ vs. flow through, $1.08 \pm 0.05$ vs. $0.41 \pm 0.02, P=0.0003$, Figure $5 \mathrm{a}, \mathrm{b})$. As immunofluorescent stains performed in Figure 3, affinitypurified anti-pp65 $336-439$ antibodies reproduced all ANA stains found in direct serum-staining (Figure 3), including speckled (Figure 5c1,c7), chromatin (Figure 5c2,c8), centriole (Figure $5 c 3, c 9$ ) or MSA II (Figure $5 c 4, c 10$ ) stains. Antibodies purified from flow through or anti-pp651-167 immunized sera, however, did not produce noticeable nuclear staining patterns (Figure 5c5,c11 and Figure 5c6, 


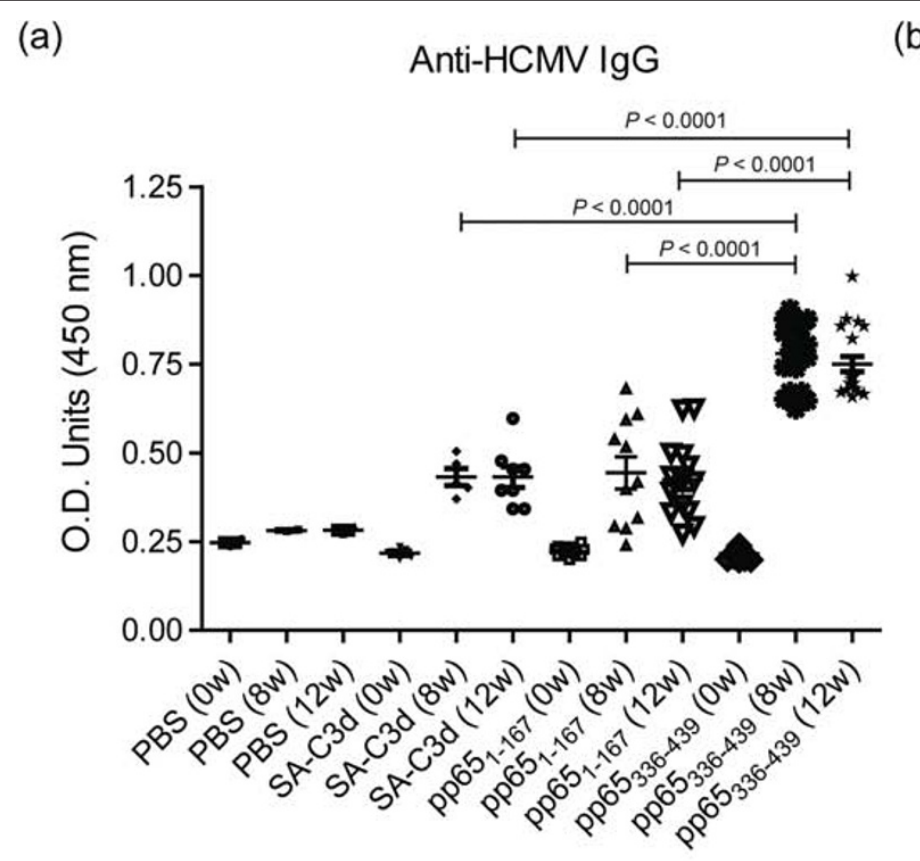

(b)
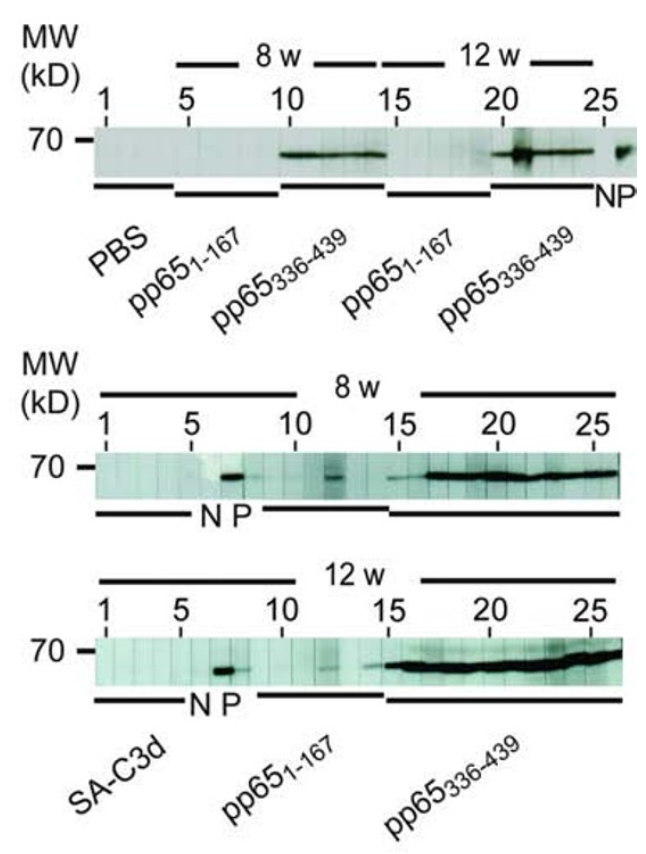

(c)

Anti-HeLa IgG

(d)
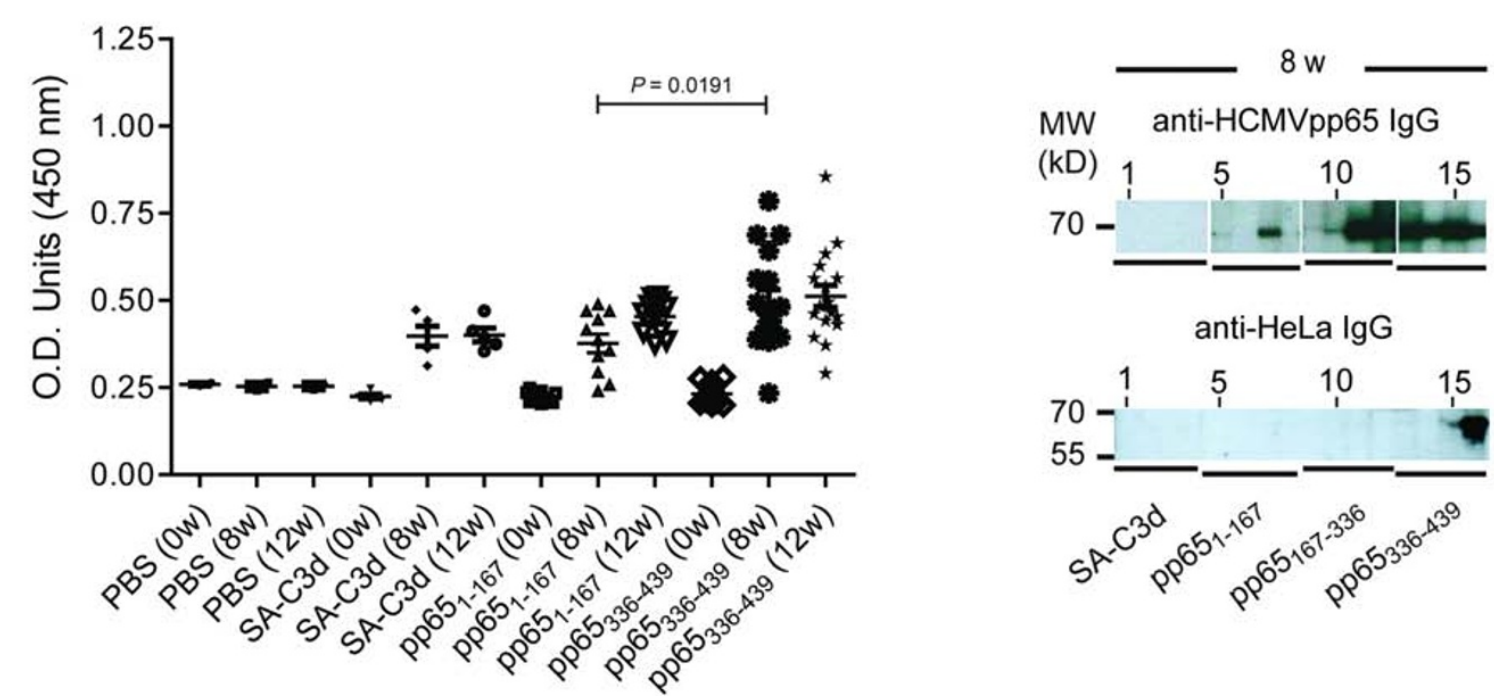

Figure 2 Detection of anti-HCMVpp65 antibody by ELISA and immunoblot assay in immunized BALB/c mice. The lgG against HCMVpp65 or HeLa extract from pp651-167 $(n=11)$, pp65 $336-439(n=17)$, SA-C3d $(n=5)$ or PBS $(n=2)$ immunized mice. (a) ELISA assays for anti-HCMV reactivity against purified HCMV virions. Sera were 500X diluted and positivity was defined by mean +3 s.e.m. of SA-C3d-immunized sera. O.D.450 $>0.50$ was considered to be positive. (b) Immunoblot analysis on anti-HCMV reactivity against purified HCMV virions. Sera were 500X diluted. Top panel: pp65 1-167 $(n=5), \operatorname{pp65}_{336-439}(n=5)$ and PBS $(n=2)$. Lane 1 to 2 and 3 to 4, PBS-immunized sera at 8 and 12 weeks, lane 5 to 9 and 15 to 19 , pp65 to 1-167-immunized sera, lane 10 to 14 and 20 to 24 , pp65 $336-439$-immunized sera, lane 25, N: 1,000X diluted healthy control serum, lane 26, P: 1,000X diluted SLE patient's serum. Bottom panel: SA-C3d $(n=5), \operatorname{pp}_{1-167}(n=6)$ and pp65 $5_{336-439}(n=12)$. Lane 1 to 5, SA-C3dimmunized sera, lane 6, N: 1,000X diluted healthy control serum, lane 7 to 8, P: 1,000X diluted SLE patients' sera, lane 9 to 14, pp651-167immunized sera, lane 15 to 26, pp65 $336-439$-immunized sera. (c) ELISA assays for anti-HeLa reactivity against total HeLa lysate. Sera were 500X diluted. O.D.450 $>0.48$ was considered to be positive. (d) Immunoblot analysis with mouse sera at eight weeks post-immunization against HCMV and total HeLa lysate. Top panel: purified HCMV virion blot. Bottom panel: total HeLa lysate blot. Lane1 to 4, C3d-immunized sera, lane 5 to 8 ,

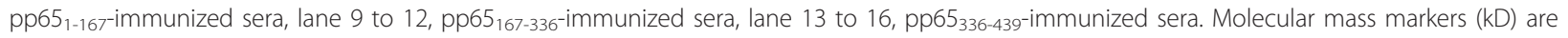
shown on the left. MW: molecular weight. w: weeks of post-immunization. Graphs depict mean \pm s.e.m. values. Unpaired Student $t$ test was performed. Results with a $P$-value of $<0.05$ were considered to be significant. These results are representative of triplicated experiments. 


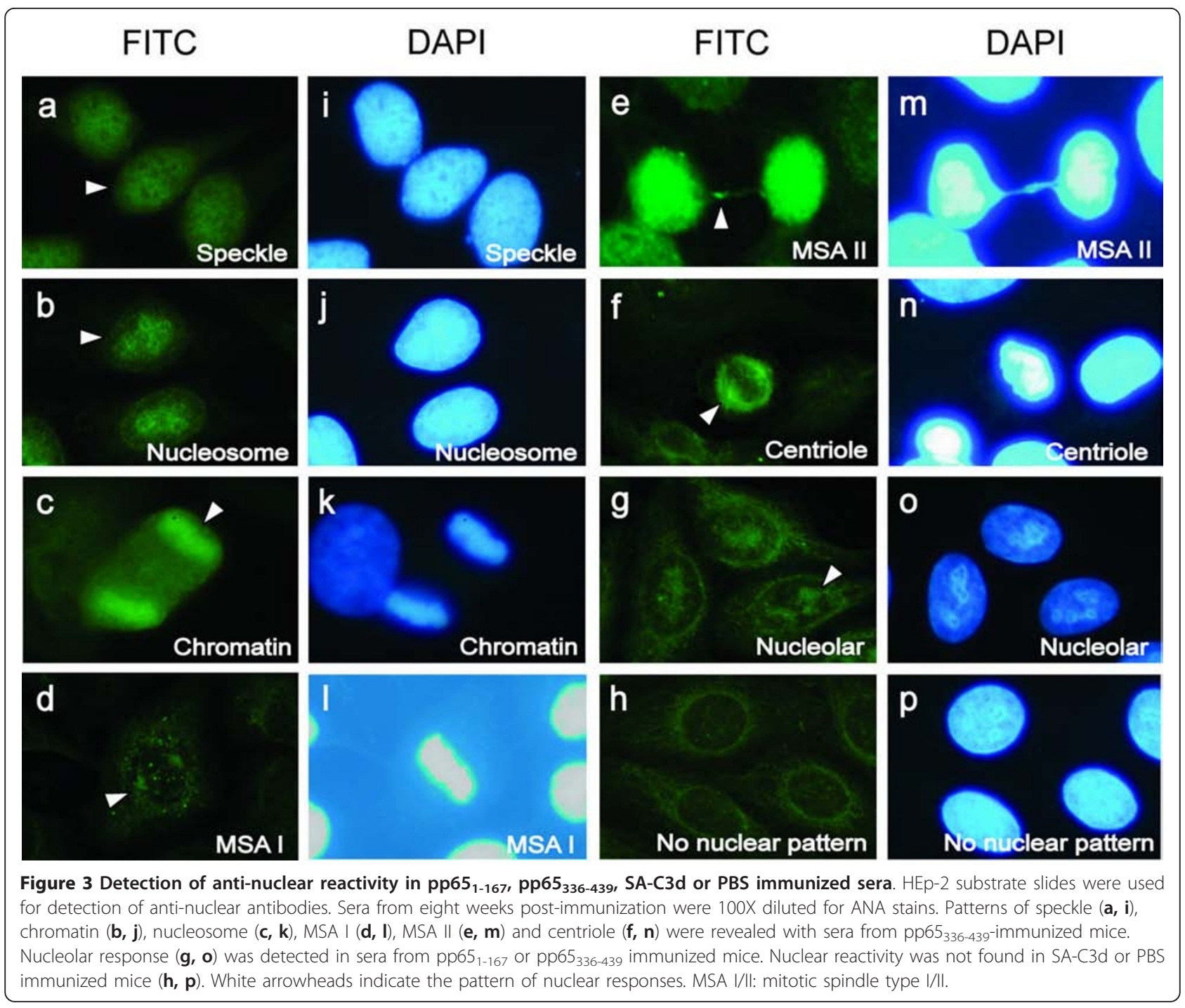

c12). In addition to nuclear stain, affinity-purified antipp65 $336-439$ antibody also possessed reactivity to dsDNA as ELISA and Crithidia luciliae slides demonstrated (0.49 \pm 0.02 , Figure $6 a, b)$. The difference of anti-dsDNA activity between purified anti-pp65 $5_{1-167}$ antibody and flow through

Table 4 The summary of ANA patterns in mice against to cellular components

\begin{tabular}{|c|c|c|c|c|}
\hline Nuclear patterns & $\begin{array}{l}\text { pp65 } 1-167 \\
n=11\end{array}$ & $\begin{array}{l}\text { pp65 } \\
n=17\end{array}$ & $\begin{array}{l}\text { SA-C3d } \\
n=5\end{array}$ & $\begin{array}{l}\text { PBS } \\
n=2\end{array}$ \\
\hline Speckle & 0 & 5 & 0 & 0 \\
\hline Nucleosome & 0 & 4 & 0 & 0 \\
\hline Chromatin & 0 & 4 & 0 & 0 \\
\hline Centriole & 0 & 6 & 0 & 0 \\
\hline MSA I & 0 & 4 & 0 & 0 \\
\hline MSA II & 0 & 10 & 0 & 0 \\
\hline Nucleolar & 4 & 14 & 0 & 0 \\
\hline
\end{tabular}

MSA I, mitotic spindle type I, MSA II, mitotic spindle type II were insignificant (pp65 $5_{1-167}$ vs. flow through, $0.12 \pm 0.01$ vs. $0.15 \pm 0.01)$.

Deposition of immunoglobulin or immune complexes on glomeruli is a characteristic of early nephritis and is often found in SLE patients [24]. Immunofluorescent stains with anti-mouse IgG in renal section showed that pp65 $336-439$-immunized mice developed signs of deposition of immune complex on glomeruli (Figure $6 \mathrm{c} 1$ ). A total of 6 of 17 pp $65_{336-439}$-immunized mice showed IgG deposition on glomeruli, but such stains were not found in pp65 ${ }_{1-167}(0 / 11$, Figure 6c2), SA-C3d (0/5, Figure $6 \mathrm{c} 3)$ or PBS $(0 / 2$, Figure $6 \mathrm{c} 4)$ treated animals. We did not observe clinical symptoms, such as proteinuria or lesions on the kidneys of immunofluorescent-positive mice. Nevertheless, it is noteworthy that the levels of immunoglobulin deposition showed positive correlation to the titers of the anti-dsDNA antibody (data not shown). 


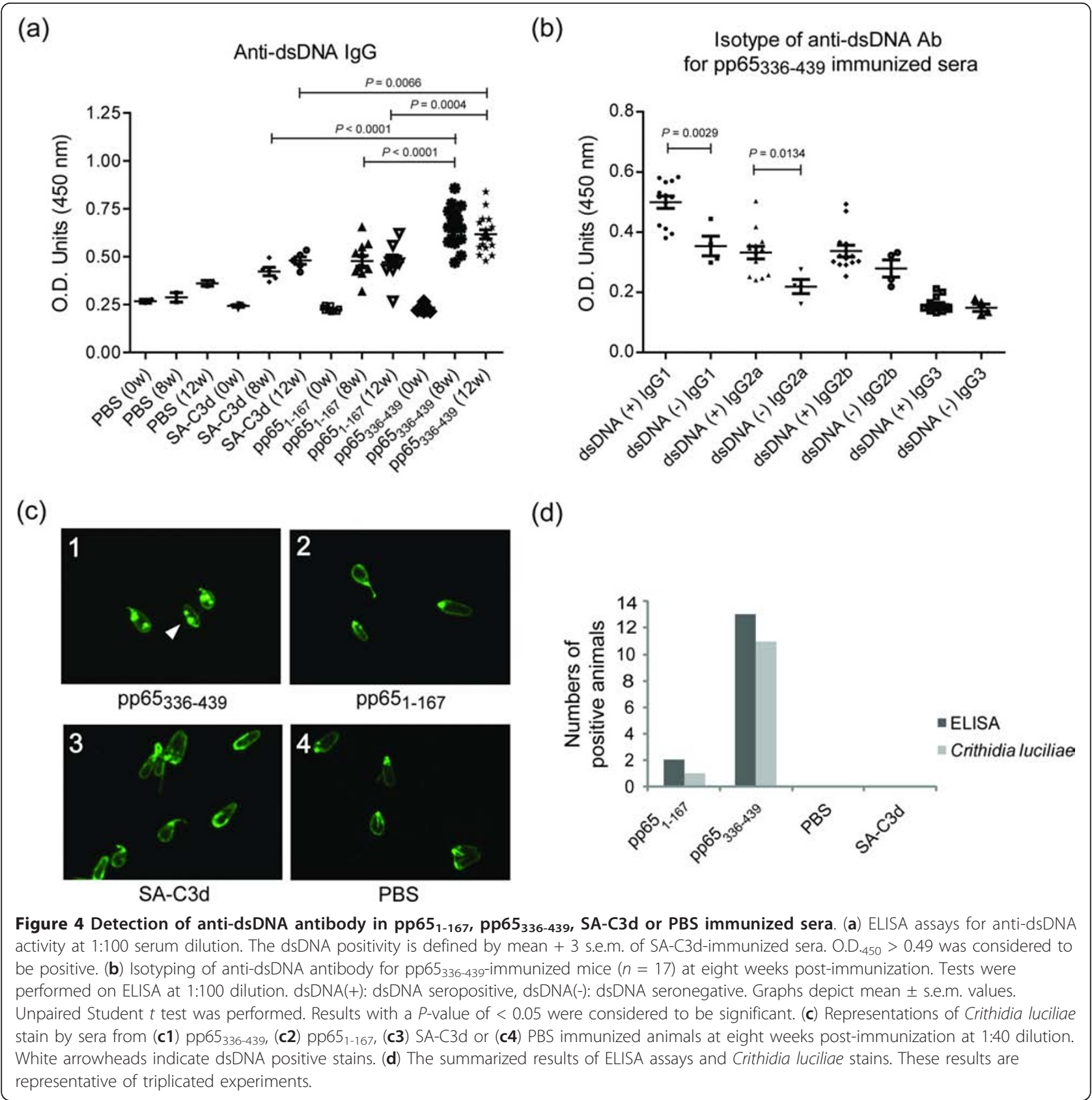

Yeast two-hybrid showed the binding of HCMVpp65 336 439 binds to diverse HeLa proteins

Immediately after infection, HCMVpp65 was transported into the nucleus and migrated to nucleolus [25]. We hypothesized that the pp65 $336-439$ fragment may complex to intracellular antigens during infection. Immunoblotting and yeast two-hybrid verified this hypothesis and showed the association between HeLa proteins and pp65336-439 (Figure 7, Table 5). Such binding was not found on either pp651-167 or protein-free tests. Among those pp65336-439 binding colonies from yeast two-hybrid, 10 were verified as nucleic acid binding proteins, heat-shock proteins and apoptosis-related proteins (Table 5).

\section{Discussion}

HCMVpp65 is a strong T-cell antigen to most human and several epitopes within this antigen have been mapped from normal population [14,26]. Up to now, 28 CTL epitopes have been reported for pp65 and four of them are located within pp65 $336-439$ [14]. The elevation of anti-pp65 antibody is not a rare phenomenon to 
(a)

\section{Anti-HCMV activity by affinity purified antibody}

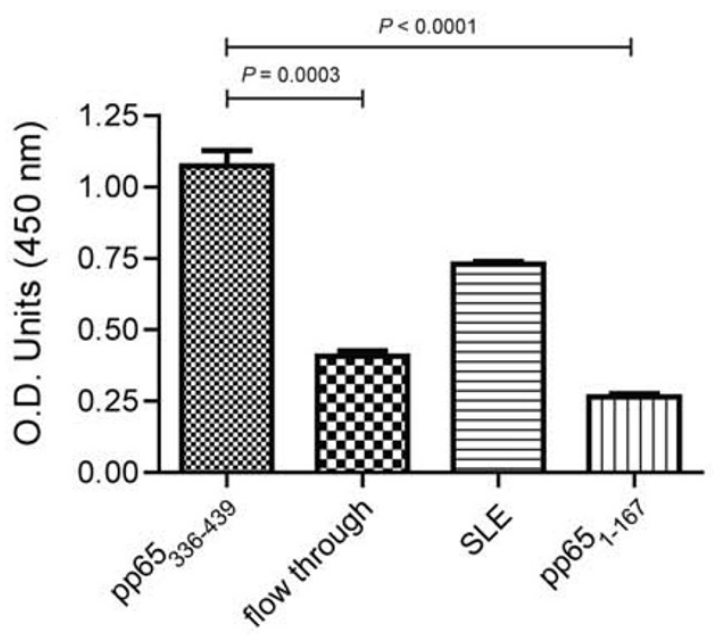

(c)
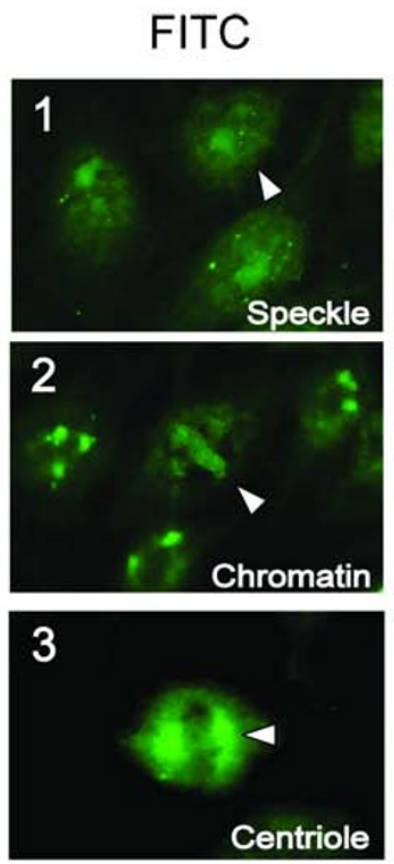

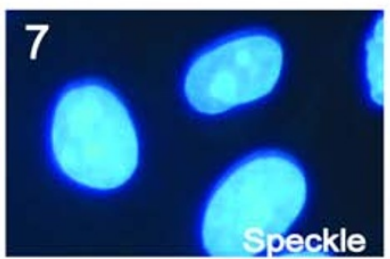

DAPI
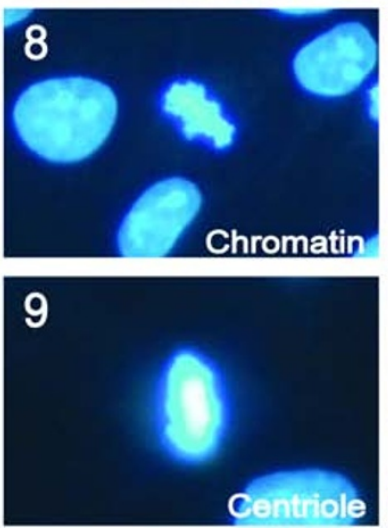

(b)

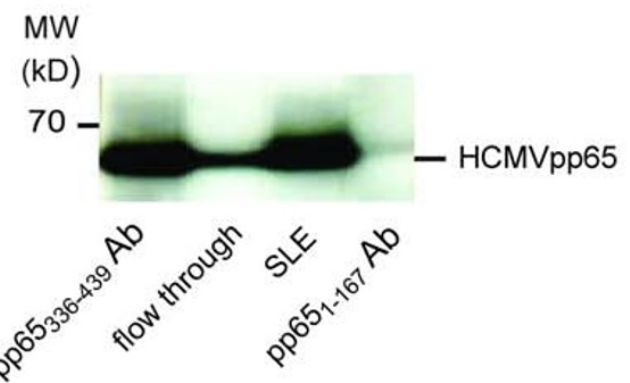

FITC
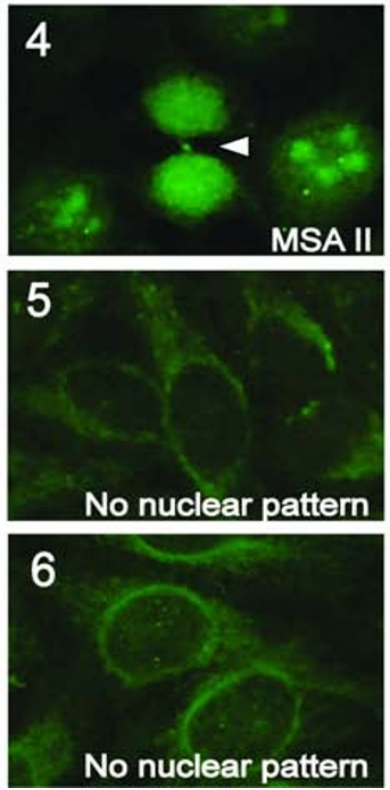
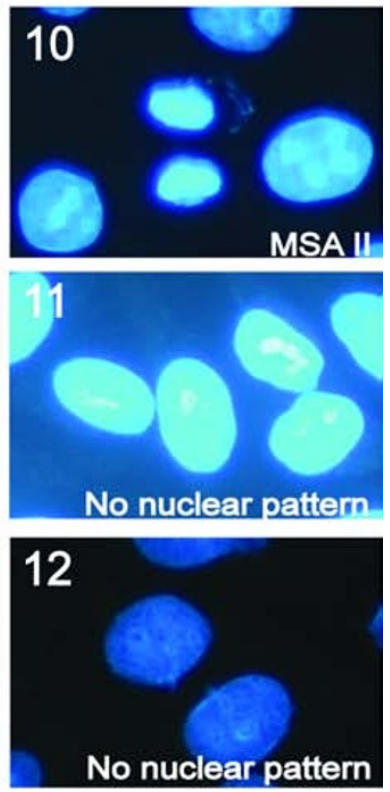

Figure 5 Detection of anti-nuclear reactivity in pp65 $5_{1-167}$ or pp65 $5_{336-439}$ specific antibodies from eight weeks post-immunization sera. (a) ELISA assays of affinity purified anti-pp65 $336-439$ antibody (pp65 $336-439$ ), anti-pp65 1 167 antibody (pp65 1 167), SLE patients' sera (SLE) and flow through against purified HCMV virions. Graphs depict mean \pm s.e.m. values. Unpaired Student $t$ test was performed. Results with a $P$-value of $<$

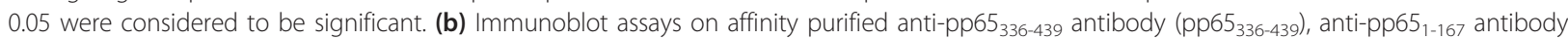
(pp65 1-167), SLE patients' sera (SLE) and flow through against purified HCMV virions. Molecular mass markers (kD) are shown on the left. MW:

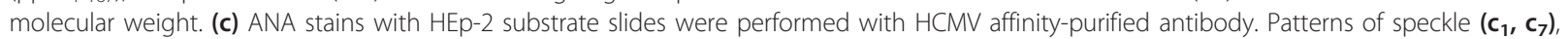
chromatin $\left(\mathbf{c}_{\mathbf{2}}, \mathbf{c}_{\mathbf{8}}\right)$, centriole $\left(\mathbf{c}_{\mathbf{3}}, \mathbf{c}_{\mathbf{9}}\right)$ and MSA $\|\left(\mathbf{c}_{\mathbf{4}}, \mathbf{c}_{\mathbf{1 0}}\right)$ were revealed with affinity purified anti-pp65 $5_{336-439}$ antibodies. Nuclear pattern was not found in flow through $\left(\mathbf{c}_{5}, \mathbf{c}_{11}\right)$ or affinity-purified anti-pp651-167 antibody $\left(\mathbf{c}_{6}, \mathbf{c}_{12}\right)$ stains. White arrowheads indicate the patterns of nuclear response. MSA II: mitotic spindle type $\|$. 
(a)

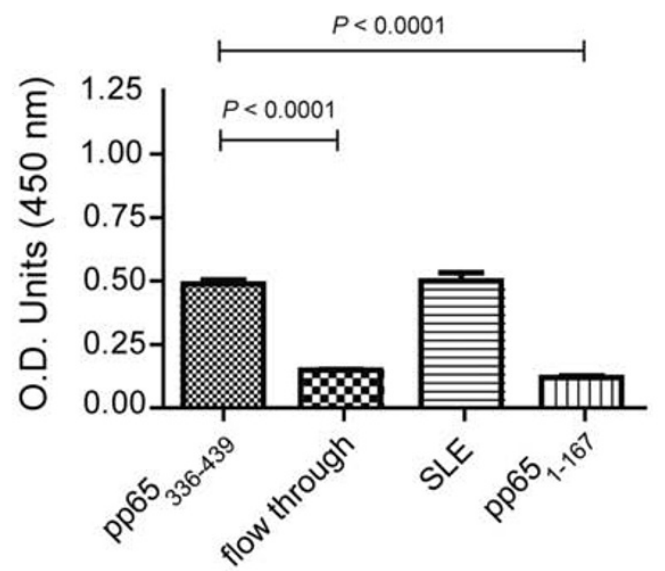

(b)

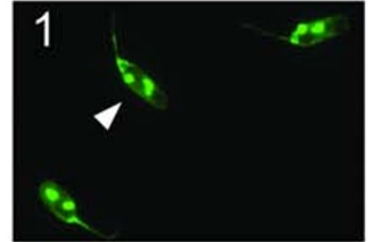

pp65336-439

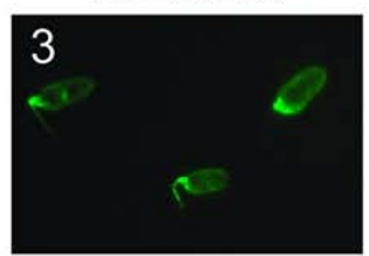

flow through

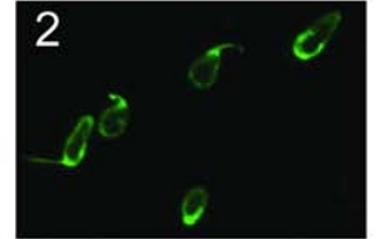

pp651-167

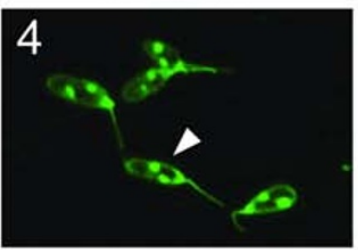

SLE

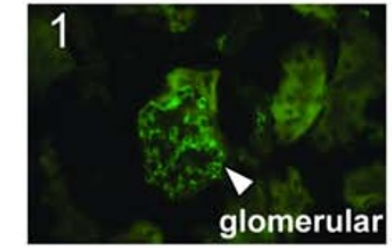

(c)

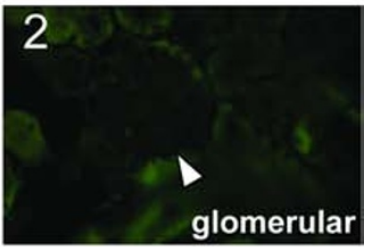

pp65336-439

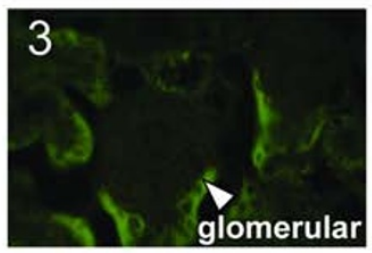

SA-C3d

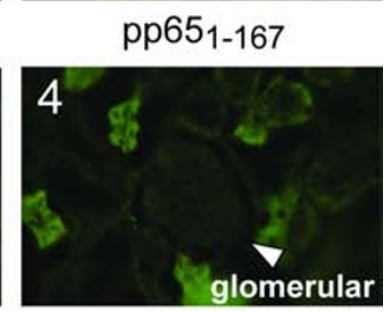

PBS

Figure 6 The cross-reactivity of purified anti-pp65 ${ }_{336-439}$ or anti-pp65 ${ }_{1-167}$ antibody to dsDNA. (a) ELISA assays for affinity-purified antipp65 $336-439$ antibody (pp65 336-439), anti-pp65 $1-167$ antibody (pp651-167), flow through and SLE patients' sera (SLE) against dsDNA. Graphs depict mean \pm s.e.m. values. Unpaired Student $t$ test was performed. Results with a $P$-value of $<0.05$ were considered to be significant. (b)

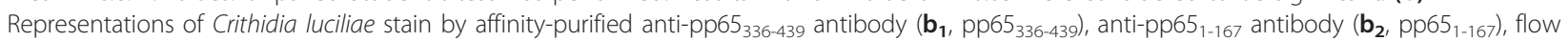
through $\left(\mathbf{b}_{\mathbf{3}}\right)$ and SLE patients' sera ( $\left.\mathbf{b}_{\mathbf{4}}, \mathrm{SLE}\right)$ against dsDNA. White arrowheads indicate the positive stains. (c) Representations of Immunofluorescent stain for immunoglobulin deposition on glomerular by pp65 $336-439$ ( $\left.\mathbf{c}_{1}\right)$ immunized mice, pp65 1-167 $\left(\mathbf{c}_{2}\right)$ immunized mice, SAC3d $\left(\mathbf{c}_{3}\right)$ immunized mice or PBS $\left(\mathbf{c}_{4}\right)$ controls. Kidneys were collected at 20 weeks of age. White arrowheads indicate antibody deposition on glomerular. dsDNA: double-stranded DNA.

persons during primary HCMV infection or reactivation, but such activity is rarely sustained [27]. In this study, we reported at least one SLE-specific, autoimmuneprone B-cell epitope within HCMVpp65 $336-439$. B-cell epitope(s) within this region may not be unique to SLE sera, since our mapping has not ruled out the possible existence of epitope(s) within the junctions of fragments or conformational epitope(s). Elevated and sustained anti-pp65 antibody in SLE patients and induction of autoimmunity via immunization in both of BALB/c and NZB/W mice suggesting a hypothesis that humoral immunity toward pp65 antigen may possess a pathogenic potential [15].

Transient immunity to pp65 can be detected in the sera of BALB/c mice immunized with either full-length pp65 or pp65 $636-439$ in Freund's adjuvant [15]. To study the effect of anti-pp65 antibody, we have immunized $\mathrm{BALB} / \mathrm{c}$ mice with either full-length or truncated pp65 


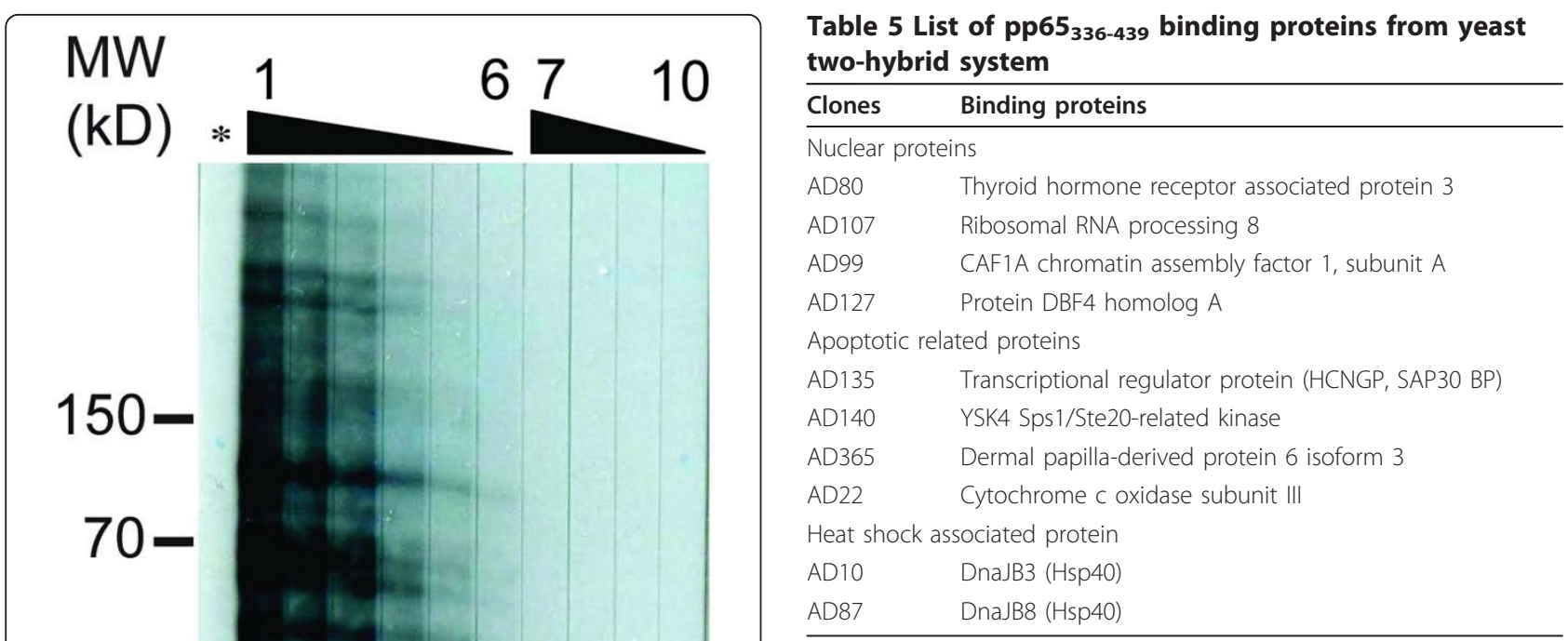

peptides [15]. In addition, a potent adjuvant that is capable of eliciting strong and sustained immunity to an antigen of low immunogenicity, such as pp65, is preferred. The C3d is an effective molecular adjuvant that appears safe and acceptable for use in vaccines [17]. Dempsey et al. showed that C3d-conjugated hen egg lysozyme (HEL) exhibited up to a 1,000-fold increase in immunogenicity than HEL alone [16]. We found that immunization of pp65 $336-439$ peptide with C3d could sustain the humoral immunity to pp65 $336-439$, and such immunization also elicited cross-reactive antibody against host cellular proteins, including dsDNA and its associated proteins on non-autoimmune BALB/c mice.

The etiology of autoimmunity is complex, either the cross-reactivity by anti-pp65 $336-439$ antibody to multiple nuclear components or epitope spreading by binding of pp65 to host proteins may contribute to the out spread of auto-reactive antibodies. We could not identify significant sequence homology between pp $65_{336-439}$ and many nuclear targets recognized by SLE sera. Diamond et al. showed that decapeptide DWEYSVWLSN could induce anti-dsDNA IgG and deposition of immunoglobulin on glomeruli [28].

McClain et al. reported that the immunization with either EBNA-1 could induced specific anti-Ro and antiEBNA-1 ${ }_{52-72}$ antibody in experimental animal, but EBNA$1_{52-72}$, with this structure, shared no amino acid sequence homology with Ro [3]. Sunder et al. revealed that immunization of EBNA-1 not only induced anti-EBNA-1 antibody in mice, but also exhibited cross-reactive antibodies to both $\mathrm{SmB} / \mathrm{B}^{\prime}$ and dsDNA [29]. These studies suggested the similarity of amino acid sequence is not a requirement for mimicry-induced autoimmunity.

Our BALB/c mice developed sustained antibodies to pp65 $336-439$ and nuclear components following immunization. Our immunization scheme not only sustained the anti-pp65 activity, but also induced high titers of 
antibodies to nuclear components, including the nucleosome, centriole and chromatin. Such weak anti-nuclear responses were found on few animals never exposed to pp65336-439. This weak anti-nuclear activity is likely due to adjuvant-induced polyclonal activation because neither ANA activity nor the Crithidia luciliae stain was found from affinity-purified anti-pp651-167 antibody. Cross-reactivity between a foreign antigen and an autoantigen is a characteristic of mimicry-induced autoimmunity [30]. Our affinity purification results demonstrated that the anti-pp65 $336-439$ antibodies cross-react to several nuclear antigens, including dsDNA, suggesting that mimicry could play a part in the pp65-induced tolerance break. The anti-dsDNA antibody, particularly IgG2a, was reported to SLE nephritis and also identified from our pp65 $336-439$-immunized BALB/c [31,32]. Nevertheless, the direct relation to nephritis by anti-pp65 $336-439$ initiated anti-dsDNA antibody of IgG2 isotype was not studied in this work. The anti-dsDNA antibody from pp65 $336-439^{-}$ immunized mice was detected as early as four weeks, suggesting that pp65 $336-439$ is a potent inductor of crossreactivity. The Crithidia luciliae stain has been the golden standard to anti-dsDNA antibody. Of 17 pp65 $336-$ 439-immunized mice, 11 and 13 mice were positive for the Crithidia luciliae stains and ELISA assays, respectively. All Crithidia luciliae-positive mouse sera also possessed high titers of anti-dsDNA activity by ELISA assays, confirming the significant elevated anti-dsDNA reactivity in pp65336-439-immunized animals.

The peptide-induced immunity, which cross-reacts with both dsDNA and $\alpha$-actinin, has been described and its pathogenesis was illustrated [33]. Similar to antiDWEYSVWLSN antibody, affinity-purified anti-pp65 336 439 antibody from pp65 336 -439-immunized animals crossreacted with dsDNA on both Crithidia luciliae stains and ELISA assays. Such anti-dsDNA reactivity was not found in pp65 $65_{1-167}$ or adjuvant immunized animals. To the best of our knowledge, HCMV has not been reported to induce the anti-dsDNA antibody. The pathogenicity of pp65336-439-induced anti-dsDNA antibody on BALB/c animals was not fully examined by this study. Nevertheless, we found precipitation of immune complexes on glomeruli at 12 weeks post-immunization (20 weeks of age), and noticed positive correlation of anti-dsDNA titers to the complex precipitation (data not shown). This finding implies that an early stage of renal pathogenesis that resembles SLE nephritis may have been induced by pp65336-439-mediated cross-reactive antibody. Arbuckle et al. have revealed that anti-dsDNA antibody could be found as early as nine years before the diagnosis of SLE [22]. The asymptomatic existence of anti-dsDNA activity in our animals suggests an extended observation is required to demonstrate the clinical consequences by pp65 immunization. Genetics plays an essential role on pathogenesis of autoimmunity that might also explain the lack of clinical symptoms on our animals following immunization [34].

In addition to mimicry, epitope spreading could be another driving force to pp65336-439-induced autoimmunity. The T-antigen of human polyomaviruses has been shown to complex with nucleosomes of infected cells during viral replication. These nucleosomes/T-antigen complexes are subsequently targeted by immune responses and become a catalyst for cross-reactive antibodies against both virus and host [35]. At HCMV infection, pp65 is imported to the nucleus immediately via two nuclear localization sequences: pp65 $65_{418-438}$ and pp65 537-561 [36]. The pp65 has been demonstrated to bind to metaphase-arrested chromosomes in the pp65expressing fibroblasts during productive virus infection [37]. These findings prompted us to hypothesize that pp65 may not only bind to cellular proteins, but also form immune-complexes to DNA or other nuclear components. As expected, pp65 $336-439$ bound multiple cellular proteins including nucleic acid binding proteins, nuclear proteins, apoptosis-related proteins and heat-shock proteins (Table 5). It is noteworthy that nuclear proteins and nucleic acid binding proteins are common targets to autoimmunity, and abnormal apoptosis has been associated with autoimmunity [38]. These findings suggest that antigen-bound cellular proteins shared high probability of becoming immunogenic and provide a mechanism for subsequent development of autoimmunity. Therefore, binding to intracellular proteins by full-length or fragmented pp65 may not only generate immunecomplexes (virus/host) that are subsequently targeted by antiviral antibodies but also increase the chance of epitope spreading and lead to autoimmunity in persons with susceptible genetic backgrounds.

\section{Conclusions}

The antibody against HCMVpp65 $380-439$ antibody is rare in healthy populations but is a common feature among SLE sera. Through immunization of pp65336-439 with C3d as adjuvant, we were able to sustain the antibody titers to pp65 $5_{336-439}$ peptide and demonstrate cross-reactivity of anti-pp65 antibody to nuclear components, including dsDNA on BALB/c mice. Yeast two-hybrid analysis revealed that pp65336-439 could bind to nuclear proteins, suggesting the immune-complexes of pp65 and nuclear proteins may be part of the trigger to autoimmunity. Although none of the experimental animals developed SLE-like clinical symptom, deposition of immunoglobulin was identified from pp65 336 -439-immunized animals at 12 weeks post-immunization. Therefore, a sustained humoral immunity to pp65 may present a risk to individuals with a background predisposed to SLE. 


\section{Abbreviations}

ANAs: anti-nuclear antibodies; C3d: complement 3d; CFA: complete Freund's adjuvant; $\mathrm{CnBr}$ : cyanogen bromide; CTD: connective tissue disease; dsDNA: double-stranded DNA; EBNA-1: Epstein-Barr virus nuclear antigen 1; EBV: Epstein-Barr virus; ELISA: Enzyme Linked Immunosorbent Assay; FITC: fluorescein isothiocyanate; HCMV: human cytomegalovirus; HEL: hen egg lysozyme; HRP: horseradish peroxidase; IFA: incomplete Freund's adjuvant MSA-1/II: mitotic spindle type I/II; OPD: o-phenylenediamine dihydrochloride; PBS: phosphate-buffered saline; pp65: phosphoprotein 65; RA: rheumatoid arthritis; RT: room temperature; SA: streptavidin; SLE: systemic lupus erythematosus; SmB/B': Smith antigen B/B'; snRNP: small nuclear ribonucleoprotein; SS: Sjögren's syndrome; SSc: systemic sclerosis; YNB: yeast nitrogen base.

\section{Acknowledgements}

We thank Dr. YL Juang for technical suggestions. The yeast strains and the related materials in the yeast two-hybrid experiment were supported by Dr. YL Juang. This work was undertaken at Tzu-Chi University and supported by Grant TCIRP 95002-03 from Tzu-Chi University.

\section{Author details}

${ }^{1}$ Institute of Medical Science, Tzu-Chi University, No. 701, Sec. 3, Zhongyang Rd., Hualien City, Hualien County 970, Taiwan. Institute of Microbiology Immunology and Biochemistry, Tzu-Chi University, No. 701, Sec. 3, Zhongyang Rd., Hualien City, Hualien County 970, Taiwan. ${ }^{3}$ The National Laboratory Animal Center (NLAC), No. 128, Sec. 2, Academia Rd., Nangang Dist., Taipei City 115, Taiwan. ${ }^{4}$ Development Center of Biotechnology, No.101, Ln. 169, Kangning St., Xizhi Dist, New Taipei City 221, Taiwan.

\section{Authors' contributions}

MC, SLW and AHH jointly contributed to the design of the study. AHH performed ELISA, Western blot and immunofluorescence. YJJ carried out the yeast two-hybrid. CTL participated in the tissue stains. AHH, MC and SLW were responsible for data analysis and interpretations. AHH and MC wrote the manuscript. All authors read and approved the final manuscript.

\section{Competing interests}

The authors declare that they have no competing interests.

Received: 23 March 2011 Revised: 6 September 2011

Accepted: 11 October 2011 Published: 11 October 2011

\section{References}

1. Poole BD, Scofield RH, Harley JB, James JA: Epstein-Barr virus and molecular mimicry in systemic lupus erythematosus. Autoimmunity 2006, 39:63-70.

2. Poole BD, Gross T, Maier S, Harley JB, James JA: Lupus-like autoantibody development in rabbits and mice after immunization with EBNA-1 fragments. J Autoimmun 2008, 31:362-371.

3. McClain MT, Heinlen LD, Dennis GJ, Roebuck J, Harley JB, James JA: Early events in lupus humoral autoimmunity suggest initiation through molecular mimicry. Nat Med 2005, 11:85-89.

4. Khoshnevis M, Tyring SK: Cytomegalovirus infections. Dermatol Clin 2002, 20:291-299, vii.

5. Oldstone MB, Nerenberg M, Southern P, Price J, Lewicki H: Virus infection triggers insulin-dependent diabetes mellitus in a transgenic model: role of anti-self (virus) immune response. Cell 1991, 65:319-331.

6. Osame K, Takahashi Y, Takasawa H, Watanabe S, Kishimoto M, Yasuda K, Kaburagi Y, Nakanishi K, Kajio H, Noda M: Rapid-onset type 1 diabetes associated with cytomegalovirus infection and islet autoantibody synthesis. Intern Med 2007, 46:873-877.

7. Cheng HM, Khairullah NS: Induction of antiphospholipid autoantibody during cytomegalovirus infection. Clin Infect Dis 1997, 25:1493-1494.

8. Zhu J: Cytomegalovirus infection induces expression of $60 \mathrm{KD} / \mathrm{Ro}$ antigen on human keratinocytes. Lupus 1995, 4:396-406.

9. Newkirk MM, van Venrooij WJ, Marshall GS: Autoimmune response to U1 small nuclear ribonucleoprotein (U1 snRNP) associated with cytomegalovirus infection. Arthritis Res 2001, 3:253-258.

10. Curtis HA, Singh T, Newkirk MM: Recombinant cytomegalovirus glycoprotein $\mathrm{gB}$ (UL55) induces an autoantibody response to the U1-70 kDa small nuclear ribonucleoprotein. Eur J Immunol 1999, 29:3643-3653.
11. McLaughlin-Taylor E, Pande H, Forman SJ, Tanamachi B, Li CR, Zaia JA, Greenberg PD, Riddell SR: Identification of the major late human cytomegalovirus matrix protein pp65 as a target antigen for $\mathrm{CD} 8^{+}$virusspecific cytotoxic T lymphocytes. J Med Virol 1994, 43:103-110.

12. Tanaka N, Kimura H, Hoshino Y, Nishikawa K, Kojima S, Nishiyama Y, Morishima T: Expression of tegument protein pp65 of human cytomegalovirus (CMV) and its application to the analysis of viralspecific cellular immunity in CMV-infected individuals. Arch Virol 2002, 147:2405-2417.

13. Khattab BA, Lindenmaier W, Frank $R$, Link $H$ : Three T-cell epitopes within the C-terminal 265 amino acids of the matrix protein pp65 of human cytomegalovirus recognized by human lymphocytes. J Med Virol 1997, 52:68-76.

14. Kondo E, Akatsuka Y, Kuzushima K, Tsujimura K, Asakura S, Tajima K, Kagami Y, Kodera Y, Tanimoto M, Morishima Y, Takahashi T: Identification of novel CTL epitopes of CMV-pp65 presented by a variety of HLA alleles. Blood 2004, 103:630-638.

15. Chang M, Pan MR, Chen DY, Lan JL: Human cytomegalovirus pp65 lower matrix protein: a humoral immunogen for systemic lupus erythematosus patients and autoantibody accelerator for NZB/W F1 mice. Clin Exp Immunol 2006, 143:167-179.

16. Dempsey PW, Allison ME, Akkaraju S, Goodnow CC, Fearon DT: C3d of complement as a molecular adjuvant: bridging innate and acquired immunity. Science 1996, 271:348-350.

17. Green TD, Montefiori DC, Ross TM: Enhancement of antibodies to the human immunodeficiency virus type 1 envelope by using the molecular adjuvant C3d. J Virol 2003, 77:2046-2055.

18. Yu M, Li da J, Wang XL, Yuan MM, Zhu Y, Yao XY, Li HP: [Molecular adjuvant C3d up-regulates both B7-1 and B7-2 expression on Raji cells]. Fen Zi Xi Bao Sheng Wu Xue Bao 2006, 39:77-82.

19. Olmsted JB: Affinity purification of antibodies from diazotized paper blots of heterogeneous protein samples. J Biol Chem 1981, 256:11955-11957.

20. Linnik MD, Hu JZ, Heilbrunn KR, Strand V, Hurley FL, Joh T: Relationship between anti-double-stranded DNA antibodies and exacerbation of renal disease in patients with systemic lupus erythematosus. Arthritis Rheum 2005, 52:1129-1137.

21. Arbuckle MR, James JA, Kohlhase KF, Rubertone MV, Dennis GJ, Harley JB: Development of anti-dsDNA autoantibodies prior to clinical diagnosis of systemic lupus erythematosus. Scand J Immunol 2001, 54:211-219.

22. Arbuckle MR, McClain MT, Rubertone MV, Scofield RH, Dennis GJ, James JA, Harley JB: Development of autoantibodies before the clinical onset of systemic lupus erythematosus. N Engl J Med 2003, 349:1526-1533.

23. Bijl M, Dijstelbloem HM, Oost WW, Bootsma H, Derksen RH, Aten J, Limburg PC, Kallenberg CG: IgG subclass distribution of autoantibodies differs between renal and extra-renal relapses in patients with systemic lupus erythematosus. Rheumatology (Oxford) 2002, 41:62-67.

24. Hurd ER, Ziff M: Quantitative studies of immunoglobulin deposition in the kidney, glomerular cell proliferation and glomerulosclerosis in NZB/ NZW F1 hybrid mice. Clin Exp Immunol 1977, 27:261-268.

25. Cui Z, Zhang K, Zhang Z, Liu Y, Zhou Y, Wei H, Zhang XE: Visualization of the dynamic multimerization of human Cytomegalovirus pp65 in punctuate nuclear foci. Virology 2009, 392:169-177.

26. Provenzano M, Sais G, Bracci L, Egli A, Anselmi M, Viehl CT, Schaub S, Hirsch HH, Stroncek DF, Marincola FM, Spagnoli GC: A HCMV pp65 polypeptide promotes the expansion of $\mathrm{CD}^{+}$and $\mathrm{CD} 8^{+} \mathrm{T}$ cells across a wide range of HLA specificities. I Cell Mol Med 2009, 13:2131-2147.

27. Landini MP, Lazzarotto T, Xu J, Geballe AP, Mocarski ES: Humoral immune response to proteins of human cytomegalovirus latency-associated transcripts. Biol Blood Marrow Transplant 2000, 6:100-108.

28. Putterman $C$, Diamond B: Immunization with a peptide surrogate for double-stranded DNA (dsDNA) induces autoantibody production and renal immunoglobulin deposition. J Exp Med 1998, 188:29-38.

29. Sundar K, Jacques S, Gottlieb P, Villars R, Benito ME, Taylor DK, Spatz LA: Expression of the Epstein-Barr virus nuclear antigen-1 (EBNA-1) in the mouse can elicit the production of anti-dsDNA and anti-Sm antibodies. $J$ Autoimmun 2004, 23:127-140.

30. Deshmukh US, Kannapell CC, Fu SM: Immune responses to small nuclear ribonucleoproteins: antigen-dependent distinct B cell epitope spreading patterns in mice immunized with recombinant polypeptides of small nuclear ribonucleoproteins. J Immunol 2002, 168:5326-5332. 
31. Garcia CO, Molina JF, Gutierrez-Urena S, Scopelitis E, Wilson WA, Gharavi AE, Espinoza LR: Autoantibody profile in African-American patients with lupus nephritis. Lupus 1996, 5:602-605.

32. Winkler TH, Henschel TA, Kalies I, Baenkler HW, Skvaril F, Kalden JR: Constant isotype pattern of anti-dsDNA antibodies in patients with systemic lupus erythematosus. Clin Exp Immunol 1988, 72:434-439.

33. Zhao Z, Weinstein E, Tuzova M, Davidson A, Mundel P, Marambio P, Putterman C: Cross-reactivity of human lupus anti-DNA antibodies with alpha-actinin and nephritogenic potential. Arthritis Rheum 2005, 52:522-530,

34. Mendlovic S, Brocke S, Fricke H, Shoenfeld Y, Bakimer R, Mozes E: The genetic regulation of the induction of experimental SLE. Immunology 1990, 69:228-236.

35. Andreassen K, Bredholt G, Moens U, Bendiksen S, Kauric G, Rekvig OP: T cell lines specific for polyomavirus $\mathrm{T}$-antigen recognize $\mathrm{T}$-antigen complexed with nucleosomes: a molecular basis for anti-DNA antibody production. Eur J Immunol 1999, 29:2715-2728.

36. Schmolke $S$, Drescher $P$, Jahn $G$, Plachter B: Nuclear targeting of the tegument protein pp65 (UL83) of human cytomegalovirus: an unusual bipartite nuclear localization signal functions with other portions of the protein to mediate its efficient nuclear transport. J Virol 1995, 69:1071-1078.

37. Dal Monte P, Bessia C, Landini MP, Michelson S: Expression of human cytomegalovirus ppUL83 (pp65) in a stable cell line and its association with metaphase chromosomes. J Gen Virol 1996, 77:2591-2596.

38. Maniati E, Potter P, Rogers NJ, Morley BJ: Control of apoptosis in autoimmunity. J Pathol 2008, 214:190-198.

doi:10.1186/ar3481

Cite this article as: Hsieh et al:: Fragment of tegument protein pp65 of human cytomegalovirus induces autoantibodies in BALB/c mice. Arthritis Research \& Therapy 2011 13:R162.

\section{Submit your next manuscript to BioMed Central and take full advantage of:}

- Convenient online submission

- Thorough peer review

- No space constraints or color figure charges

- Immediate publication on acceptance

- Inclusion in PubMed, CAS, Scopus and Google Scholar

- Research which is freely available for redistribution

Submit your manuscript at www.biomedcentral.com/submit 